\title{
The effect of excipients on the stability and aerosol performance of salmon calcitonin dry powder inhalers prepared via the spray freeze drying process
}

\author{
NARGES POURSINA \\ ALIREZA VATANARA* \\ MOHAMMAD REZA ROUINI \\ KAMBIZ GILANI \\ ABDOLHOSSEIN ROUHOLAMINI \\ NAJAFABADI \\ Department of Pharmaceutics \\ Faculty of Pharmacy, Tehran \\ University of Medical Sciences \\ Tehran, Iran
}

Accepted October 15, 2015

Published online May 16, 2016

\begin{abstract}
Spray freeze drying was developed to produce dry powders suitable for applications such as inhalation delivery. In the current study, the spray freeze drying technique was employed to produce inhalable salmon calcitonin microparticles. Effects of the carrier type, concentration of hydroxyl propyl- $\beta$-cyclodextrin and the presence of Tween 80 on the chemical and structural stability, as well as on the aerosol performance of the particles were investigated. The results indicated that hydroxyl propyl- $\beta$-cyclodextrin had the most important effect on the chemical stability of the powder and strongly increased its stability by increasing its concentration in the formulation. Chemically stable formulations (over $90 \%$ recovery) were selected for further examinations. Fluorescence spectroscopy and circular dichroism suggested that the formulations were structurally stable. Aerosol performance showed that the Tween-free powders produced higher fine particle fraction values than the formulations containing Tween (53.7 vs. $41.92 \%$ for trehalose content and 52.85 vs. $43.06 \%$ for maltose content).

Keywords: salmon calcitonin, inhalation, spray freeze drying, hydroxypropyl- $\beta$-cyclodextrin, fine particle fraction, stability
\end{abstract}

Salmon calcitonin (sCT) is a 32-amino acid linear polypeptide hormone with a 1-7 disulfide bridge (1). It has been approved for the treatment of osteoporosis and Paget's disease; its injectable solution (Calcimar, Miacalcin) and nasal spray (Fortical, Miacalcin) are commercially available for this purpose. Parenteral delivery is an inconvenient route, especially for drugs such as SCT that have short half-lives after administration (15-20 min) and require frequent injections to retain a pharmacological effect. The nasal form shows 3 to $5 \%$ efficacy over the parenteral dosage form (2).

Pulmonary delivery of peptides and proteins is a noninvasive alternative method (3) and a promising route because the lung has an enormous absorptive surface area, very

*Correspondence; e-mail: narges.poursina@gmail.com 
thin diffusion path to the bloodstream, high blood flow and low level of metabolic activity; it also avoids first-pass hepatic metabolism (4).

Several reports on the respiratory delivery of $\mathrm{sCT}$ were focused on the bioavailability of this peptide in the lungs. Malkhlof et al. (5) showed that nanoparticles of glycol chitosan and its thiolated derivatives increased the mucoadhesive properties of sCT. Yamamoto $e t$ al. (6) showed that elimination of chitosan-modified PLGA nanospheres of calcitonin was significantly longer than unmodified PLGA nanospheres because of their stronger mucoadhesion properties and the opening of the intercellular tight junctions. Varshosaz et al. (7) attempted to increase the bioavailability of inhaled sCT using poly(methyl vinyl ether-altmaleic acid) as a mucoadhesive polymer, which increased its hypocalcemic effect.

Several particle engineering methods have produced powders suitable for inhalation, including micronization and blending, controlled solvent crystallization, supercritical fluid processing, spray drying and so on. Spray freeze drying (SFD) is a technique for producing respirable particles of peptides or proteins (8). The method combines atomization and freezing followed by ice sublimation under vacuum. The process formulates relatively spherical particles with a high specific surface area and low density with adjustable size distribution (9). These small spherules with a small aerodynamic size are more likely to reach deeper lung tissue for effective deposition (10).

SFD is a three-step technique involving atomization, rapid freezing and lyophilization. Consequently, peptides and proteins encounter stresses such as adsorption at the air liquid interface and freezing, which could lead to chemical or physical degradation (11). A common route for enhancing the stability of peptides or proteins during SFD is the addition of excipients such as sugars and surfactants (12).

The aim of the present study was to prepare SFD particles of $\mathrm{sCT}$ and assess the effect of formulation factors on the stability, physical characteristics and aerosol performance of the powders. Peptide stability was assessed using chromatography, circular dichroism and fluorescence spectroscopy. Physical characterization of stable powders was carried out using laser light diffraction and scanning electron microscopy (SEM). The aerosol performance of the formulations was evaluated using a twin stage impinger (TSI).

\section{EXPERIMENTAL}

\section{Materials}

Salmon calcitonin was purchased from Polypeptide Laboratories, USA. Acetonitrile, trehalose, maltose and hydroxyl propyl- $\beta$-cyclodextrin $(\mathrm{HP} \beta C D)$ were purchased from Sigma, Germany. Tetramethylammonium hydroxide and Tween 80 were provided by Merck, Germany, and the hydroxypropyl methylcellulose (HPMC) capsules were a kind gift from Cipla, India.

\section{Spray freeze drying}

Initially, $4 \%(\mathrm{~m} / \mathrm{V})$ aqueous solutions containing $0.5 \% \mathrm{sCT}$, a sugar carrier (trehalose or maltose), $\operatorname{HP} \beta C D(0,0.02$ and $0.04 \%)$ and Tween $80(0$ and $0.001 \%)$ were prepared as shown in Table I. In each experiment, $0.4 \mathrm{~L}$ of liquid nitrogen was poured into a 2-L glass container to produce a cryogenic vapor. The feed solution was atomized using a 2-fluid 
N. Poursina et al.: The effect of excipients on the stability and aerosol performance of salmon calcitonin dry powder inhalers prepared via the spray freeze drying process, Acta Pharm. 66 (2016) 207-218.

Table I. Formulations of spray freeze dried salmon calcitonin

\begin{tabular}{cccc}
\hline Formulation & Sugar type & HPBCD $(\%, m / m)$ & Tween $80(\%, m / V)$ \\
\hline$F_{1}$ & Trehalose & 0 & 0 \\
$F_{2}$ & Trehalose & 0.02 & 0 \\
$F_{3}$ & Trehalose & 0.04 & 0 \\
$F_{4}$ & Trehalose & 0 & 0.001 \\
$F_{5}$ & Trehalose & 0.02 & 0.001 \\
$\mathrm{~F}_{6}$ & Trehalose & 0.04 & 0.001 \\
$\mathrm{~F}_{7}$ & Maltose & 0 & 0 \\
$\mathrm{~F}_{8}$ & Maltose & 0.02 & 0 \\
$\mathrm{~F}_{9}$ & Maltose & 0.04 & 0 \\
$\mathrm{~F}_{10}$ & Maltose & 0 & 0.001 \\
$\mathrm{~F}_{11}$ & Maltose & 0.02 & 0.001 \\
$\mathrm{~F}_{12}$ & Maltose & 0.04 & 0.001 \\
\hline
\end{tabular}

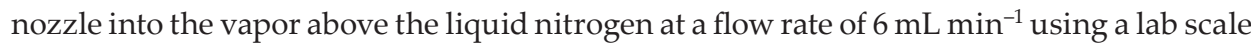
spray dryer (Buchi 191, Switzerland). The slurry formed was left on a bench until the excess nitrogen evaporated and the frozen droplets were then lyophilized in a freeze dryer (Christ, Germany). The primary drying process was performed at $-50{ }^{\circ} \mathrm{C}$ and $0.005 \mathrm{mbar}$ for $24 \mathrm{~h}$; secondary drying was performed by gradually increasing the temperature to $-20{ }^{\circ} \mathrm{C}$ over $24 \mathrm{~h}$. Powder yield was approximately $85 \%$.

\section{Salmon calcitonin stability}

Chemical stability. - The sCT content of the powders was evaluated using a RP-HPLC system (Waters; USA) and a $\mathrm{C}_{18}$ column ( $5 \mu \mathrm{m}$; $4.6 \times 150 \mathrm{~mm}$, Tosoh Bioscience, Japan) at $220 \mathrm{~nm}$. The mobile phase was composed of component A [2:5:93 (V/V/V) $1 \mathrm{~mol} \mathrm{~L}^{-1}$ tetramethylammonium hydroxide/acetonitrile/water, $\mathrm{pH}$ 2.5] and component $\mathrm{B}$ [8:500:492 $(V / V / V) 1 \mathrm{~mol} \mathrm{~L}^{-1}$ tetramethylammonium hydroxide/acetonitrile/water, $\mathrm{pH} 2.5$ ] applied as a linear gradient of $\mathrm{A} / \mathrm{B}$ from 70:30 to $47: 53$ for $20 \mathrm{~min}$. The injectable volume was $80 \mu \mathrm{L}$

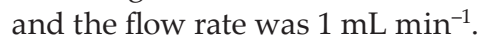

Conformational stability. - Conformational stability of chemically stable formulations (sCT recovery $>90 \%$ ) was studied using circular dichroism (CD) and intrinsic fluorescence spectroscopy.

Circular dichroism: An Aviv CD spectrometer 410 (Biomedical; US) was used to produce CD spectroscopy measurements at room temperature. A $0.02 \mathrm{~cm}$ quartz cuvette was used for far-UV CD measurements at $180-250 \mathrm{~nm}$ and a $0.1 \mathrm{~cm}$ quartz cuvette was employed for near-UV CD measurements at $250-310 \mathrm{~nm}$. The sCT concentration was $0.2 \mathrm{~g} \mathrm{~L}^{-1}$ for the near-UV region and $0.5 \mathrm{~g} \mathrm{~L}^{-1}$ for the far-UV region. Each measurement was the 
average of five replicated scans (step resolution $2 \mathrm{~nm}, 65$ each step) and the corresponding solvent spectrum was subtracted from the sample spectrum.

Intrinsic fluorescence spectroscopy: Intrinsic fluorescence spectra were obtained using a luminescence spectrometer (Perkin Elmer; USA). Intrinsic fluorescence was monitored at 300 to $400 \mathrm{~nm}$ with an excitation wavelength of $280 \mathrm{~nm}$. The excitation and emission sites were set at $10 \mathrm{~nm}$. Each sample used $1 \mu \mathrm{g}$ of salmon calcitonin to generate accumulation of five scans.

\section{Particle characterization}

Scanning electron microscopy (SEM). - Selected SFD powders were sprinkled onto a stub, dried at $25^{\circ} \mathrm{C}$ and then sputtered with gold using a sputter coater (BAL-TEC, Switzerland). The morphology of the microparticles was assessed using SEM (Mira Tescan, Czech Republic) at an accelerating voltage of $25 \mathrm{KV}$.

Particle size analysis. - Particle size of the SFD powder was assessed using a Malvern mastersizer (Malvern, UK). For this purpose, about $5 \mathrm{mg}$ of each powder was suspended in $5 \mathrm{~mL}$ of acetonitrile and sonicated in a water bath sonicator (Starsonic, Italy) for $3 \mathrm{~min}$. Measurements were carried out at obscurations of 0.15 to 0.2 in triplicate.

In vitro powder deposition. - A glass Twin stage impinger (TSI) (Copley, UK) was used to evaluate the aerodynamic behavior and deposition of stable SFD formulations. About $10 \mathrm{mg}$ of each powder sample was loaded into size 2 HPMC capsules and placed into a Cyclohaler $^{\circledR}$ dry powder inhaler. Six capsules were used per run and each run was performed in triplicate. The powders were aerosolized using a pump for $5 \mathrm{~s}$ at a flow rate of $60 \mathrm{~L} \mathrm{~min}^{-1}$.

After aerosolization, the powder deposited on the device, throat, stage 1 and stage 2 were exhaustively washed with water and the sCT content in each solution was assayed by RP-HPLC. The recovered dose (RD) was the sum of the mass of the powder assayed on the device and all parts of the TSI while the fine particle dose (FPD) was the amount of sCT deposited at stage 2 of TSI. The emitted dose (ED) was the amount of powder that exited the capsule and device into the TSI. The fine particle fraction (FPF) was the percentage of FPD in ED.

Storage stability. - To evaluate the storage stability of the sCT SFD powders, selected samples were stored in vacuum sealed glass bottles covered with aluminium foil and dented rubber caps, under different storage conditions at temperatures of $4 \pm 2{ }^{\circ} \mathrm{C}$ (refrigerator), $25 \pm 2{ }^{\circ} \mathrm{C}$ (air-conditioned room) and $45 \pm 2{ }^{\circ} \mathrm{C}$ (in a controlled oven). Samples from each of the conditions were analyzed using RP-HPLC after 3 months of storage. A triplicate set of samples was used in all cases for each of the storage conditions.

\section{Statistical analysis}

All results were expressed as mean and standard deviations of three independent samples. Multiple linear regression and one-way analysis of variance (ANOVA) tests were performed to demonstrate statistical differences $(p<0.05)$, using the SPSS software version 13 (IBM Corporation, USA). 


\section{RESULTS AND DISCUSSION}

\section{Stability of salmon calcitonin in SFD powders}

Stresses acting on the peptide during SFD can cause physical and chemical degradation. Preserving the chemical and structural integrity of these biopharmaceuticals to maintain their biological activity is a challenge (13). Appropriate selection of excipient types and ratios is a crucial factor for successful peptide and protein formulation.

\section{Chemical stability}

The salmon calcitonin content of each sample was evaluated as a stability criterion. The area under each HPLC peak was compared with the standard sCT peak and the results were reported as the percentage of salmon calcitonin primary content. Recovery percentages of SFD powders are shown in Fig. 1.

The results revealed that the sugar carrier type did not significantly affect powder stability $(p>0.05)$ and that there was no difference between the stabilizing effect of maltose "as a reducing sugar" and trehalose immediately after SFD. The HP $\beta C D$ concentration had a significant effect on the chemical stability of the $\mathrm{SCT}$ powders and the sCT content of the processed powders increased in proportion to the increase in $\operatorname{HP} \beta C D(p<0.05)$.

Although there are no other reports on the effects of cyclodextrins on the stability of peptides or proteins during SFD, it appears that these excipients follow the same pattern as for lyophilization. Cyclodextrins have been investigated in concentrations of 0.001 to $10 \%(\mathrm{~m} / \mathrm{V})$ in peptide- and protein-lyophilized powders and can act as lyoprotectants or surface acting agents, depending on the concentration in the formulation (14). Surfactantlike effects of cyclodextrins have been recognized in freeze drying of some proteins such as $\beta$-galactosidase and lactate dehydrogenase. In these cases, the stabilizing effect of $\mathrm{HP} \beta C D$ on the protein was shown to be stronger than that of other CDs $(15,16)$. It should be also mentioned that this type of $\mathrm{CD}$ has been proven to be safe in toxicological studies (15). Accordingly, the protective effect of $\mathrm{HP} \beta \mathrm{CD}$ on $\mathrm{sCT}$ as a peptide was evaluated in the present study. In the study, HP $\beta C D$ was used at 0.02 and $0.04 \%(m / V)$ in a combination of sugar carriers as lyoprotectants. Fig. 1 shows that the best stabilizing effect within the tested conditions was that provided by the concentration of $0.04 \%$.

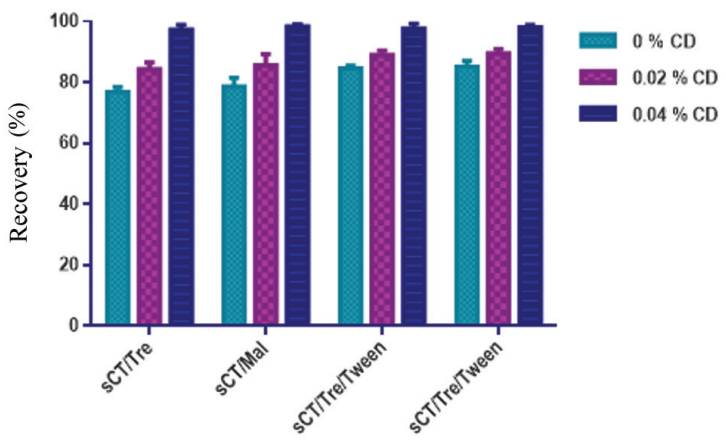

Fig. 1. Chemical stability of spray freeze dried sCT formulations. 
The other excipients used to improve the preservation of peptide structure during atomization and drying are surfactants. They compete with peptides for adsorption of interfaces such as water-air or ice and decrease peptide exposure to unfolding and aggregation (17). A number of studies have examined the stabilizing effect of surfactants during spray drying and freeze drying but there is little data about their effects in combination with other excipients during SFD.

Addition of Tween 80 to formulations containing 0 or $0.02 \%$ HP $\beta C D$ increased the percentage of $\mathrm{sCT}$ recovery $(p<0.05)$. No significant difference was found in the percentage of recovery of $\mathrm{sCT}$ in formulations containing $0.04 \% \mathrm{HP} \beta \mathrm{CD}$ in the presence of Tween 80. This could be a result of the higher stabilizing effect of cyclodextrins in this concentration, which can cover the surfactant role of Tween 80 . Powders containing $0.04 \% \mathrm{HP} \beta \mathrm{CD}$ $\left(\mathrm{F}_{3}, \mathrm{~F}_{6}, \mathrm{~F}_{9}, \mathrm{~F}_{12}\right)$, regardless of the type of sugar and the presence of Tween 80 , showed more than $90 \%$ recovery and were selected for further investigations.

\section{Structural stability}

Circular dichroism. - CD spectroscopy can provide useful information about the secondary and tertiary structures of peptides and proteins $(18,19)$. Figs. 2 and 3 show the solvent-subtracted near and far UV-CD spectra of the chemically stable formulations compared to unprocessed sCT. Fig. 2 shows that the overall shapes of the far-UV spectra were very similar to each other and to unprocessed sCT. The mean residue ellipticity was evaluated for quantitative comparison of the secondary structure. Data of all the formulations and unprocessed sCT showed a similar secondary structure of approximately $9 \% \alpha$-helix, $27 \% \beta$-sheet, $28 \%$ turns and the remaining structure comprised of random coils.

CD spectroscopy was used in the near-UV region (250-350 nm) to prove the conformational stability of SFD formulations. The reference-subtracted near-UV spectra of the chemically stable formulation vs. the unprocessed sCT are shown in Fig. 3. The predominant contribution of sCT is to be expected from the Tyr 22 (20). The solvent-subtracted near-UV spectra of the samples were comparable to each other and to the unprocessed $\mathrm{sCT}$. The near UV-CD spectra indicated that the tertiary structure of sCT formulations did not alter considerably during SFD.

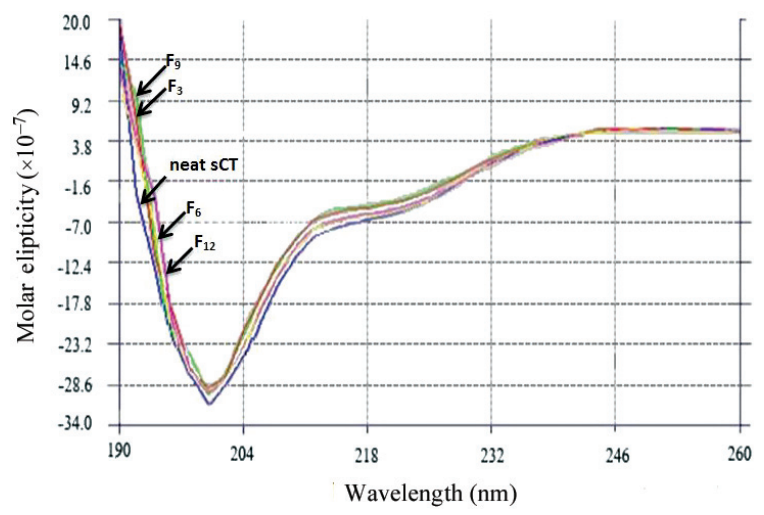

Fig. 2. Far-UV spectra of formulations F3, F6, F9 and F12 compare to neat sCT. 


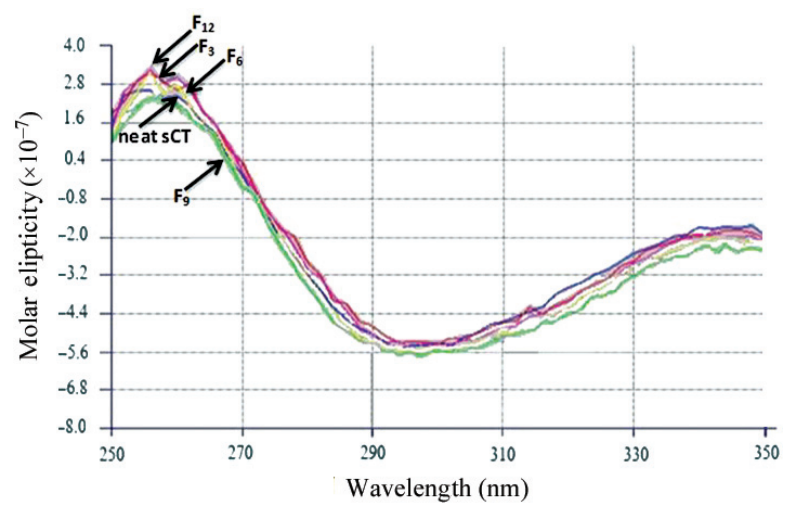

Fig. 3. Near-UV spectra of formulations F3, F6, F9 and F12 compare to neat sCT.

Intrinsic fluorescence spectroscopy. - Intrinsic fluorescence is used in peptide studies to assess the folding, a property of the tertiary structure. Information on the tertiary structure of a protein, specifically the degree of unfolding, is characterized by this method. Peptides that contain hydrophilic amino acids such as tryptophan, tyrosine or phenylalanine are used in intrinsic fluorescence measurement assays. The fluorescence intensity gives useful information about the location of these fluorophores (21). Modifications in the formulation, like the addition of excipients, can cause conformational changes resulting in a right or left shift (red or blue shift) and a decrease or increase in fluorescence intensity (22).

Fig. 4 shows the fluorescence spectra of the chemically stable SFD formulation (chemical stability $>90 \%$ ) vs. the reference sCT. The spectra of these formulations produced a lambda

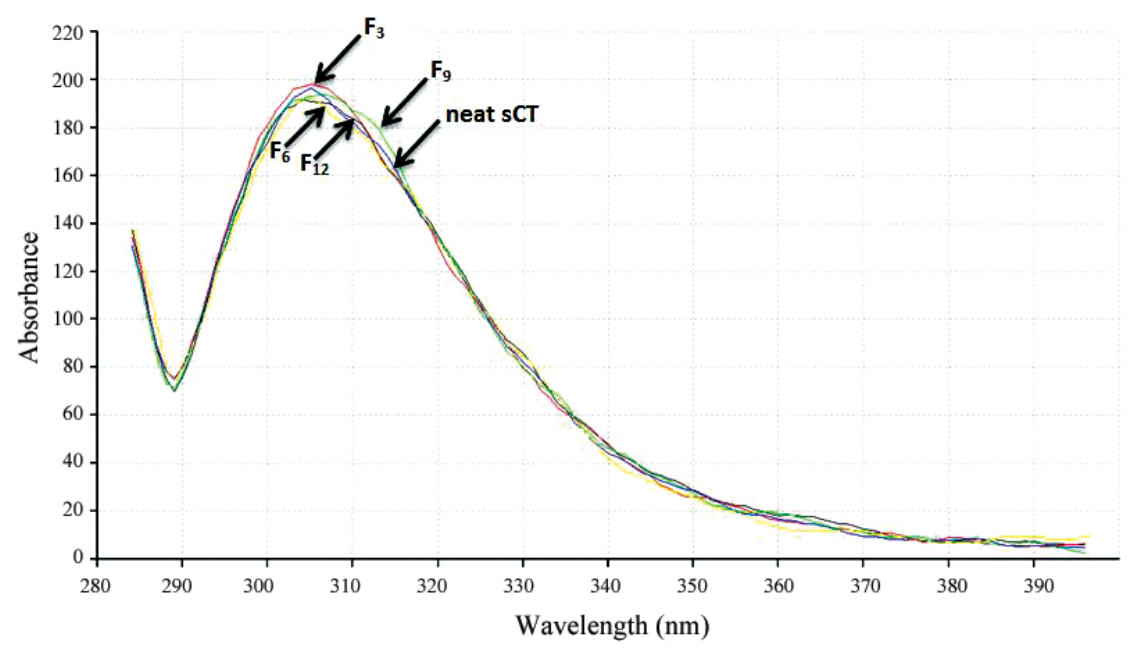

Fig. 4. Fluorescence spectra of formulations F3, F6, F9 and F12 compared to neat sCT. 
max (approximately $257 \mathrm{~nm}$ ) with similar shapes that showed no perturbation in the conformational structure of the sCT. In addition to the chemical stability, the data confirmed that $\mathrm{HP} \beta \mathrm{CD}$, at a concentration of $0.04 \%(\mathrm{~m} / \mathrm{V})$, in combination with disaccharide lyoprotectants can fully stabilize salmon calcitonin during SFD with or without surfactant.

\section{Physical characteristics of SFD powder}

Scanning electron microscopy (SEM). - Morphologies of the selected powders were studied using SEM (Fig. 5). All samples were observed to be highly porous and spherical in shape, with rough surfaces similar to the previously-reported microparticles prepared by SFD (23). The morphology did not alter with a change in carrier type and the trehalose and maltose formulations resembled each other. The highly porous structure of these microparticulates makes them candidates for inhalation because of their effective aerodynamic properties.

Fig. 5 shows that the morphology of particles containing Tween 80 was somewhat different from that of surfactant-free particles. Alteration of the surfactant-dependent morphology has been described by Shoyele et al. (24). It may be that more agglomerates exhibited in surfactant containing powders makes them more cohesive than surfactant free particles.

Size distribution. - Particle sizes of the powders are presented in Table II. The volumetric mean particle size of all powders, as determined by laser diffraction analysis, was 15-16

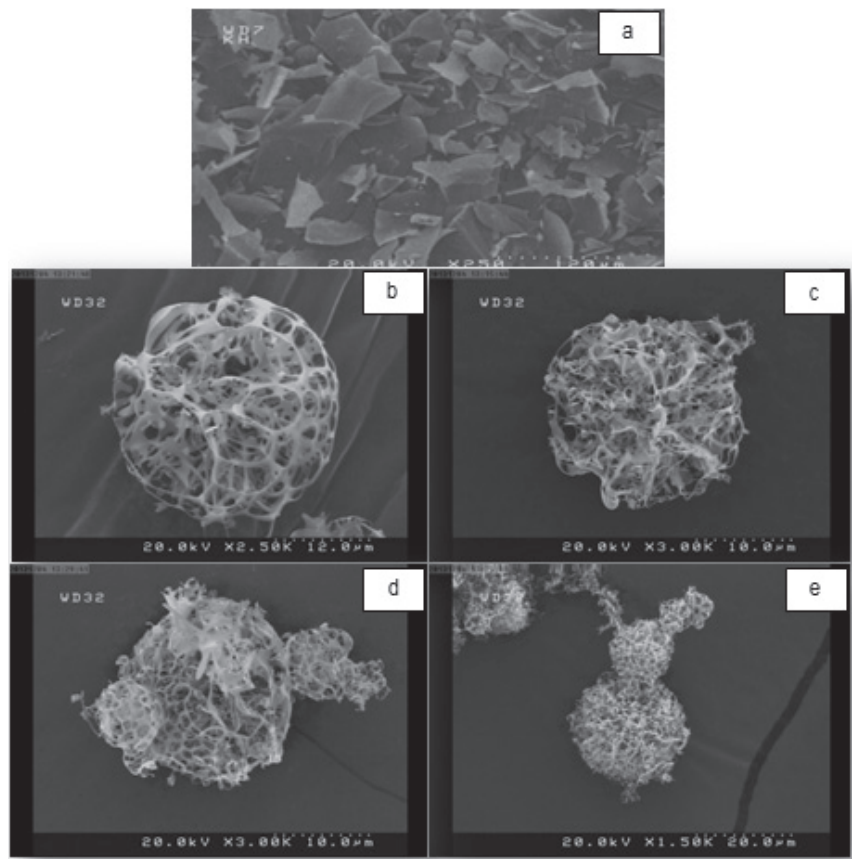

Fig. 5. Scanning electron micrographs of salmon calcitonin: a) unprocessed salmon calcitonin, b) F3, c) F6, d) F9 and e) F12. 
N. Poursina et al.: The effect of excipients on the stability and aerosol performance of salmon calcitonin dry powder inhalers prepared via the spray freeze drying process, Acta Pharm. 66 (2016) 207-218.

Table II. Particle size distribution of SFD formulations

\begin{tabular}{ccccl}
\hline Sample & span & $\mathrm{d} 10 \%(\mu \mathrm{m})$ & $\mathrm{d} 50 \%(\mu \mathrm{m})$ & $\mathrm{d} 90 \%(\mu \mathrm{m})$ \\
\hline $\mathrm{F}_{3}$ & $1.18 \pm 0.05$ & $7.07 \pm 0.05$ & $16.06 \pm 0.03$ & $26.17 \pm 0.06$ \\
$\mathrm{~F}_{6}$ & $1.20 \pm 0.08$ & $6.63 \pm 0.15$ & $15.07 \pm 0.09$ & $24.83 \pm 0.08$ \\
$\mathrm{~F}_{9}$ & $1.10 \pm 0.08$ & $6.17 \pm 0.08$ & $15.31 \pm 0.05$ & $23.12 \pm 0.09$ \\
$\mathrm{~F}_{12}$ & $1.19 \pm 0.07$ & $6.54 \pm 0.06$ & $15.63 \pm 0.04$ & $25.23 \pm 0.06$ \\
\hline
\end{tabular}

Mean \pm SD, $n=3$

$\mu \mathrm{m}$, which is far from the ideal particle size for inhalation. Nevertheless, as shown in Fig. 5 , the SFD particles were very porous, which made them suitable for inhalation. Furthermore, their relatively large size could help them escape from alveolar macrophages $(8,10)$.

In this manner, the carrier type or the presence of Tween 80 had no effect on the size of dry powders $(p<0.05)$. Moreover, the SFD powders showed relatively narrow size distributions (span 1.16), which was suitable for inhalation.

In vitro deposition of SFD powders

In general, particles with aerodynamic diameters of 1 to $5 \mu \mathrm{m}$ and a density of $\sim 1 \mathrm{~g} \mathrm{~L}^{-1}$ are suitable for inhalation (25). Eq. 1 calculates the aerodynamic diameter $\left(d_{\text {aero }}\right)$ using the geometric diameter $\left(d_{\text {geo }}\right)$, density of the particle $\left(\rho_{\mathrm{p}}\right)$, and reference density $\left(\rho_{\mathrm{p}}=\right.$ density of water at $\left.1000 \mathrm{~g} \mathrm{~L}^{-1}\right)$. Shape factor $X$ depends on the sphericity of the particles and equals 1 for spherical and $>1$ for non-spherical particles.

$$
d_{\text {aero }}=d_{\text {geo }} \sqrt{\frac{\sigma p}{\sigma_{0} x}}
$$

SEM shows that the particles were extremely porous, which makes $\rho_{\mathrm{p}}$ very small and the aerodynamic diameter considerably smaller than the geometric diameter. If the particles are assumed to be spherical, the aerodynamic diameter will be approximately 20 to $40 \%$ of the geometrical diameter, depending on the porosity and density of the particles (23).

Table III shows that all powders have relatively acceptable fine particle fractions (FPF) (> $40 \%$ ). Since FPF is an indicator of in vivo alveolar deposition, all powders showed proper inhalation behavior.

Table III. Summary of aerodynamic particle size distribution for sCT

\begin{tabular}{ccccc}
\hline Sample & RD $(\mu \mathrm{m})$ & $\mathrm{ED}(\mu \mathrm{m})$ & FPD $(\mu \mathrm{m})$ & FPF $(\%)$ \\
\hline $\mathrm{F}_{3}$ & $47.44 \pm 2.78$ & $45.98 \pm 2.56$ & $24.40 \pm 4.45$ & $53.70 \pm 1.82$ \\
$\mathrm{~F}_{6}$ & $50.93 \pm 3.28$ & $47.43 \pm 2.08$ & $19.88 \pm 4.06$ & $41.92 \pm 3.04$ \\
$\mathrm{~F}_{9}$ & $48.75 \pm 2.93$ & $46.77 \pm 2.45$ & $24.72 \pm 0.87$ & $52.85 \pm 2.13$ \\
$\mathrm{~F}_{12}$ & $46.36 \pm 4.36$ & $44.40 \pm 3.47$ & $19.12 \pm 2.83$ & $43.6 \pm 2.91$ \\
\hline
\end{tabular}

Mean \pm SD, $n=3$. 


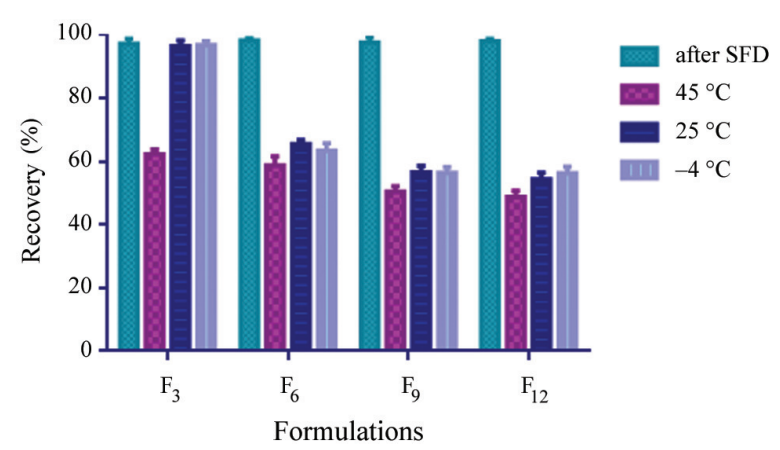

Fig. 6. Chemical stability of sCT formulations after three month storage in different conditions $(45,25$ and $\left.-4^{\circ} \mathrm{C}\right)$.

No significant difference in FPF was found between trehalose and maltose containing powders $(p>0.05)$. This can be attributed to the similar shape and size of the powders containing these sugar carriers. Tween-free powders produced higher FPF values than formulations containing Tween. This could be a result of increased agglomeration in the particles containing Tween, which limits dispersion (24).

\section{Storage stability of SFD particles}

Formulations were stored at 4,25 and $45^{\circ} \mathrm{C}$ for 12 weeks to determine their stability. Storage of all the formulations at $45^{\circ} \mathrm{C}$ resulted in a large decrease in the chemical stability of sCT (Fig. 6). The chemical stability of $\mathrm{F}_{3}(\mathrm{sCT} / \mathrm{Tre} / \mathrm{HP} \beta \mathrm{CD}$ ) was not affected by the 12 weeks of storage at 25 and $4{ }^{\circ} \mathrm{C}$. In contrast, the sCT content of $\mathrm{F}_{6}(\mathrm{sCT} / \mathrm{Malt} / \mathrm{HP} \beta \mathrm{CD})$ decreased dramatically after 12 weeks (Fig. 6). Maltose is a reducing sugar and the Millard reaction between its carbonyl group and the free amino acid groups of sCT probably created instability during storage (26). The presence of Tween 80 in the formulations led to equal or superior chemical stability. However, surfactants with alkyl polyoxyethylene chains such as polysorbates may undergo autoxidation, chain-shortening degradation, and formation of residual peroxides. These peroxides have been demonstrated to cause oxidation of proteins in solution and in the solid state (27). Polysorbates increase the shortterm stability of most proteins when exposed to surface-induced damage, but compromise protein stability during long-term storage, as has been reported for interleukin 2 and growth hormone $(27,28)$.

\section{CONCLUSIONS}

The results of this study demonstrate that sCT formulations containing $0.04 \% \mathrm{HP} \beta \mathrm{CD}$ can be spray freeze dried into powders having adequate chemical and structural integrity, with a highly porous shape that made them ideal for inhalation. Sugar carrier type did not alter their stability or aerosol performance. Although the addition of Tween 80 did not change the stability of sCT, both the aerosol performance and storage stability were negatively affected by this component. The optimum formulation to produce superior aerosol 
performance and stability after storage was $\mathrm{F}_{3}(\mathrm{Sct} / \mathrm{Tre} / \mathrm{HP} \beta \mathrm{CD} 0.04 \%)$. This indicated that $\mathrm{HP} \beta \mathrm{CD}$ and trehalose composition completely stabilized sCT formulations during SFD and produced large, porous microparticles with low aggregation, which are ideal for inhalation.

\section{REFERENCES}

1. J. P. Meyer, J. T. Pelton, J. Hoflack and V. Saudek, Solution structure of salmon calcitonin, Biopolymers 31 (1991) 233-241; DOI: 10.1002/bip.360310210.

2. C. L. Stevenson, Advances in peptide pharmaceuticals, Cur. Pharm. Biotechnol. 10 (2009) 122-137; DOI: $10.2174 / 138920109787048634$.

3. L. Jorgensen, E. H. Moeller, M. Van de Weert, H. M. Nielsen and S. Frokjaer, Preparing and evaluating delivery systems for proteins, Eur. J. Pharm. Sci. 29 (2006) 174-182; DOI: 10.1016/j.eps.2006.05.008.

4. Z. Antosova, M. Mackova, V. Kral and T. Macek, Therapeutic application of peptides and proteins: parenteral forever? Trends Biotech. 27 (2009) 628-635; DOI: 10.1016/j.tibtech.2009.07.009.

5. A. Makhlof, M. Werle, Y, Tozuka and H. Takeuchi, Nanoparticles of glycol chitosan and its thiolated derivative significantly improved the pulmonary delivery of calcitonin, Int. J. Pharm. 397 (2010) 92-95; DOI: 10.1016/j.ijpharm.2010.07.00.

6. H. Yamamoto, Y. Kuno, S. Sugimoto, H. Takeuchi and Y. Kawashima, Surface-modified PLGA nanosphere with chitosan improved pulmonary delivery of calcitonin by mucoadhesion and opening of the intercellular tight junctions, J. Control. Release 102 (2005) 373-381; DOI: 10.1016/j. conrel.2004010.010.

7. J. Varshosaz, M. Minaiyan and M. Forghanian, Prolonged hypocalcemic effect by pulmonary delivery of calcitonin loaded poly (methyl vinyl ether maleic acid) bioadhesive nanoparticles, Biomed. Res. Int. 2014, 1-13; DOI: 10.1155/2014/932615.

8. S. A. Shoyele and S. Cawthorne, Particle engineering techniques for inhaled biopharmaceuticals, Adv. Drug. Deliv. Rev. 58 (2006) 1009-1029; DOI: 10.1016/j.addr.2006.07.010.

9. Y. F. Maa, P. A. Nguyen, T. Sweeney, S. J. Shire and C. C. Hsu, Protein inhalation powders: spray drying vs. spray freeze drying, Pharm. Res. 16 (1999) 249-254; DOI: 10.1023/A:1018828425184.

10. D. A. Edwards, J. Hanes, G. Caponetti, J. Hrkach, A. Ben-Jebria, M. L. Eskew, J. Mintzes, D. Deaver, N. Lotan and R. Langer, Large porous particles for pulmonary drug delivery, Science 276 (1997) 1868-1872; DOI: 10.1126/science.276.5320.1868.

11. Z. Yu, K. P. Johnston and R. O. Williams III, Spray freezing into liquid versus spray-freeze drying: Influence of atomization on protein aggregation and biological activity, Eur. J. Pharm. Sci. 27 (2006) 9-18; DOI: 10.1016/j.ejps.2005.08.010.

12. F. Depreter, G. Pilcer and K. Amighi, Inhaled proteins: Challenges and perspectives, Int. J. Pharm. 447 (2013) 251-280; DOI: 10.1016/j.ijpharm.2013.02.031.

13. N. R. Maddux, S. B. Joshi, D. B. Volkin, J. P. Ralston and C. R. Middaugh, Multidimensional methods for the formulation of biopharmaceuticals and vaccines, J. Pharm. Sci. 100 (2011) 4171-4197; DOI: 10.1002/jps.22618.

14. T. Serno, R. Geidobler and G. Winter, Protein stabilization by cyclodextrins in the liquid and dried state, Adv. Drug Deliv. Rev. 63 (2011) 1086-1106; DOI: 1016/j/addr.2011.08.003.

15. J. Iwai, N. Ogawa, H. Nagase, T. Endo, T. Loftsson and H. Ueda, Effects of various cyclodextrins on the stability of freeze dried lactate dehydrogenase, J. Pharm. Sci. 96 (2007) 3140-3143; DOI: 10.1002/jps.20847.

16. K. Izutsu, S. Yoshioka and T. Terao, Stabilization of [beta]-galactosidase by amphiphilic additives during freeze-drying, Int. J. Pharm. 90 (1993) 187-194; DOI: 10.1016/0378-5173(93)90190-Q. 
17. H. R. Costantino, L. Firouzabadian, C. Wu, K. G. Carrasquillo, K. Griebenow, S. E. Zale and M. A. Tracy, Protein spray freeze drying. 2. Effect of formulation variables on particle size and stability, J. Pharm. Sci. 91 (2002) 388-395; DOI: 10.1002/jps.10059.

18. W. C. Johnson, Protein secondary structure and circular dichroism: a practical guide, Proteins 7 (1990) 205-214; DOI: 10.1002/prot.340070302.

19. P. Manavalan and W. C. Johnson, Sensitivity of circular dichroism to protein tertiary structure class, Nature 305 (1983) 831-832; DOI: 10.1038/305831a0.

20. H. R. Costantino, H. Culley, L. Chen, D. Morris, M. Houston, S. Roth, M. J. Phoenix, C. Foerder, J. S. Philo, T. Arakawa, L. Eideuschink, N. H. Andersen, G. Brandt and S. C. Quav, Development of calcitonin salmon nasal spray: similarity of peptide formulated in chlorobutanol compared to benzalkonium chloride as preservative, J. Pharm. Sci. 98 (2009) 3691-3706; DOI: 10.1002/jps.21690.

21. M. A. Capelle, R. Gurny and T. Arvinte, High throughput screening of protein formulation stability: practical considerations, Eur. J. Pharm. Biopharm. 65 (2007) 131-148; DOI: 10.1016/j.ejpb.2006.09.009.

22. J. T. Vivian and P. R. Callis, Mechanisms of tryptophan fluorescence shifts in proteins, Biophys. J. 80 (2001) 2093-2109; DOI: 10.1016150006-349(01)76183-8.

23. D. J. van Drooge, W. LJ. Hinrichs, B. H. J. Dickhoff, M. N. A. Elli, M. R. Visser, G. S. Zijlstra, W. Henddeik and H. W. Frijlink, Spray freeze drying to produce a stable Delta-9-tetrahydrocannabinol containing inulin-based solid dispersion powder suitable for inhalation, Eur. J. Pharm. Sci. 26 (2005) 231-240; DOI: 10.1016/j.ejps.2005.06.007.

24. S. A. Shoyele, N. Sivadas and S. A. Cryan, The effects of excipients and particle engineering on the biophysical stability and aerosol performance of parathyroid hormone (1-34) prepared as a dry powder for inhalation, AAPS Pharmscitech. 12 (2011) 304-311; DOI: 10.1208/s12249-011-9585-2.

25. D. A. Edwards, G. Caponetti, J. S. Hrkach, N. Lotan, J. Hanes and A. A. Ben-Jebria, Aerodynamically light particles for pulmonary drug delivery, U.S. Pat. 5874064. 23 Feb. 1999.

26. Y. Kato, T. Matsuda, N. Kato and R. Nakamura, Maillard reaction of disaccharides with protein: suppressive effect of nonreducing and pyranoside groups on browning and protein polymerization, J. Agri. Food Chem. 37 (1989) 1077-1081; DOI: 10.1021/jf00088a057.

27. W. Wang, Y. J. Wang and D. Q. Wang, Dual effects of Tween 80 on protein stability, Int. J. Pharm. 347 (2008) 31-38; DOI: 10161j.ijpharm.2007.06.042.

28. N. B. Bam, J. L. Cleland and T. W. Randolph, Molten globule intermediate of recombinant human growth hormone: stabilization with surfactants, Biotechnol. Prog. 12 (1996) 801-809; DOI: 10.1021/ bp960068b. 